\title{
Sedimentation and light penetration interact to maintain heterogeneity of subtidal habitats: algal versus invertebrate dominated assemblages
}

\author{
Andrew D. Irving, Sean D. Connell* \\ Department of Environmental Biology, University of Adelaide, Adelaide, South Australia 5005, Australia
}

\begin{abstract}
One of the most striking and widespread patterns observed on subtidal rocky reefs is that up-facing surfaces are monopolized by algae, whereas down-facing surfaces are dominated by sessile invertebrates. This study experimentally assessed the model that light and sedimentation interact with surface orientation to maintain this pattern of habitat heterogeneity. We tested the hypothesis that if epibiotic assemblages on down-facing surfaces were rotated to face upward, then the least change in assemblage structure would occur on shaded surfaces with reduced rates of sedimentation. In general, the alternate states of algal vs invertebrate dominated assemblages appeared to be primarily maintained by light intensity, which facilitated the cover of algae on up-facing surfaces (full light) and invertebrates on down-facing surfaces (reduced light). Although sedimentation was only partially responsible for differences between habitat types, it acted as a negative disturbance on the abundance of algae and survivorship of invertebrates. When combined with differences in light intensity, high rates of sediment accumulation had slight negative effects under natural light, but under shaded conditions these negative effects were substantially increased, causing changes to the structure of the whole assemblage. This result warns that attempts to identify the effects of sedimentation in isolation from light intensity, which depends on factors such as turbidity, may not reveal the true effects of sedimentation on epibiotic assemblages. The ability of invertebrates to withstand high rates of sediment accumulation was related to their morphology, whereby erect forms growing above accumulated sediments had greater rates of survivorship than prostrate growth forms, which tended to be smothered by sediments. To properly understand the physical processes of facilitation (e.g. light intensity) and disturbance (e.g. sedimentation) we need to assess them in meaningful combinations so that explanations of assemblage structure do not create the false impression that such processes, however complex, produce only small effects relative to other processes.
\end{abstract}

KEY WORDS: Epibiota $\cdot$ Disturbance $\cdot$ Facilitation $\cdot$ Orientation $\cdot$ Physical $\cdot$ Shade Resale or republication not permitted without written consent of the publisher

\section{INTRODUCTION}

One of the most striking and widespread patterns observed on subtidal rocky reefs is that up-facing surfaces are monopolized by algae whereas down-facing surfaces are dominated by sessile invertebrates (Osman 1977, Withers \& Thorp 1977, Todd \& Turner 1986, James \& Underwood 1994, Baynes 1999). Although

*Email: sean.connell@adelaide.edu.au these habitat associations have been widely documented, few controlled, replicated field experiments have investigated the factors responsible for them. Understanding the mechanisms that explain this pattern could provide substantial insight into the variation of the ecology of subtidal habitats and the organisms that depend on them.

Differences between epibiotic assemblages on up and down-facing surfaces are likely to be correlated with numerous factors that facilitate or act as disturbances to their development including light, sedimen- 
tation, grazing and predation pressure, and water flow. Recent studies have highlighted the importance of physical factors, in particular the positive effects of shade on invertebrates (Glasby 1999b, Saunders \& Connell 2001) and the negative effects of sedimentation on algae (Airoldi \& Cinelli 1997, Irving \& Connell 2002). Potential interactions between these 2 factors are frequently ignored in tests of hypotheses about the structure of epibiotic assemblages, but they may explain a considerable proportion of the observed spatial variation among whole assemblages (i.e. algae and invertebrates). Light intensity and rates of sediment deposition are much greater on up- than down-facing surfaces, contributing to some of the observed differences in the structure of epibiotic assemblages, but it is not known whether the effect of one factor depends on the presence or absence of the other.

Phycologists have demonstrated the importance of light for the growth and development of algae (e.g. Raven 1991), and the extent to which it explains spatial variation in the abundance of algae is often accepted to be of prime importance (e.g. Reed \& Foster 1984, Kennelly 1989, Franklin \& Forster 1997). However, abundances of algae are not uniform over small spatial scales (metres), which suggests that factores other than light also have a substantial influence on algal abundance. Sediment deposition also shows considerable local variation (metres), which may correlate with algal abundance (Airoldi \& Virgilio 1998). More importantly, increased rates of sedimentation are negatively correlated with light intensity (Ruffin 1998) and because many algae colonise higly illuminated areas, interactive effects of sedimentation and light intensity may have a greater effect than either factor in isolation. To date, experiments have focused on sedimentation independent of light intensity (Airoldi \& Cinelli 1997, Airoldi \& Virgilio 1998, Umar et al. 1998, Irving \& Connell 2002), and while the results of these tests provide important quantitative information of their effects, they are quite unrevealing about interactive effects with reduced light intensity. This information is important given that in nature decreased light intensity is unlikely to occur independently of sedimentation.

Assemblages dominated by sessile invertebrates are influenced by a host of physical factors, but the effect of light intensity has yet to be fully realized. Greater recruitment, survival and subsequent diversity and abundance of sessile invertebrates tend to occur on surfaces that are shaded (Glasby 1999a,b, Saunders \& Connell 2001). Most of these tests were done on vertical surfaces (Glasby \& Connell 2001) and little is known about the effect of sedimentation on survival and abundance of sessile invertebrates on horizontal surfaces. Because sessile invertebrates are typically more diverse and abundant on shaded surfaces, sediments may be detrimental to their settlement and survival.

To date, most experimental work on the processes of facilitation (e.g. light) and disturbance (e.g. sedimentation) concerns the dynamics of space release and occupancy, and few attempts have been made to understand how these processes maintain existing assemblages without creating bare space. This study tested the hypothesis that if epibiotic assemblages on down-facing surfaces were rotated to face upward, then the least change in assemblage structure would occur under shaded treatments with reduced rates of sedimentation. A field experiment tested this prediction by manipulating light intensity and rates of sedimentation in orthogonal combinations. This allowed for the identification of the relative and interactive effects of light and sedimentation on shaping and maintaining epibiotic assemblages.

\section{MATERIALS AND METHODS}

Experimental design. The experiment was done at Outer Harbor, South Australia $\left(34^{\circ} 47^{\prime} \mathrm{S}, 138^{\circ} 28^{\prime} \mathrm{E}\right)$ in 2 phases over 165 d, March-August 2000. In the first phase, we provided horizontal surfaces for epibiota to colonise and develop naturally on their up- and downfacing orientations $(100 \mathrm{~d})$. In the second phase, we transplanted these surfaces among treatments to test which combination of shade and sedimentation best maintained assemblages that had developed on downfacing surfaces once rotated to face up ( $65 \mathrm{~d}$ ). Epibiota are defined as assemblages of marine algae and sessile invertebrates growing on these experimental surfaces.

In March, 70 fibro-cement (Hardi-flex $\left.{ }^{\circledR}\right)$ plates $(20 \times$ $20 \mathrm{~cm}$ ) were attached to a galvanised wire mesh frame $(9.6 \times 1.5 \mathrm{~m})$ secured $10 \mathrm{~cm}$ above the sandy bottom at a depth of approximately $5 \mathrm{~m}$ (mean spring tide). The plates were left for $100 \mathrm{~d}$ before assemblages of epibiota were photographed and compared on up and down-facing surfaces ( $\mathrm{n}=35$ for each orientation). Assemblages were quantified by obtaining percentage cover estimates using a $10 \times 10 \mathrm{~cm}$ grid of 100 evenly spaced points placed over each photograph and recording the taxon present directly under each point. Only the inner $10 \times 10 \mathrm{~cm}$ of each plate was sampled to avoid 'edge effects'. To ensure that the effects of orientation (up- and down-facing surfaces) were independent of plates, we used one orientation per plate.

After $100 \mathrm{~d}, 30$ of the 70 plates were vertically rotated $180^{\circ}$ and re-attached to the wire frame. At this time, rotated plates were orthogonally partitioned among 3 levels of light intensity (full shade, procedural control, and no shade) and 2 levels of sedimentation 
(natural and reduced) so that there were 5 replicate plates per treatment $(3$ light $\times 2$ sediment $\times 5$ replicates $=30$ plates). Twenty of the remaining 40 plates were used to test potential artefacts associated with the disturbance of rotation $38 \mathrm{~d}$ after rotation. Artefacts associated with rotation were tested by comparing untouched up and down-facing plates $(n=5$ for each orientation) with the up and down-facing surfaces of plates ( $\mathrm{n}=5$ for each orientation) that had been rotated $360^{\circ}$ to face their original orientation; i.e. the only difference between these treatments is that the latter plates were disturbed and the former plates were not. The remaining 20 plates were untouched for the duration of the experiment ( $65 \mathrm{~d}$ ), with 10 of these serving as controls ( $\mathrm{n}=5$ for each orientation; up and downfacing) to assess which factor or combination of experimental factors best maintained epibiotic assemblages in algal vs invertebrate dominated states. The final 10 plates were used as spare plates in case of loss.

Full shade was created with black perspex roofs $(25 \times 25 \mathrm{~cm})$ positioned $15 \mathrm{~cm}$ above the plate surface and secured with 4 galvanised rods placed at each corner. Procedural controls were of the same configuration, but clear Mylor ${ }^{\circledR}$ plastic was used because it allows the maximum penetration of a broad spectrum of UV light (unlike clear perspex) and is used in the construction of respirometer chambers used to measure algal productivity (e.g. James \& Larkum 1996, Larkum pers. comm.). Products that absorb UV light have profound effects on the survivorship of invertebrates (Jokiel 1980) and growth and distribution of algae (Beardall et al. 1998). Comparison of epibiota on plates under clear roofs to plates without roofs (open plates) was intended to indicate any effects of the shading structure in the absence of shade. The clear and black plastic roofs were cleaned of fouling organisms and any accumulated sediment every 2-3 d throughout the experimental period.

Assemblages exposed to natural rates of sedimentation were compared to those in treatments from which sediments were removed every $2-3$ d for $65 \mathrm{~d}$. Sediments were removed by gently increasing water flow over the plate surface (wafting water with one hand) until accumulated sediment had been resuspended from the plate and cleared away. The application of this treatment took $\sim 5 \mathrm{~s}$ per plate and follows the method developed by Kendrick (1991). Storms made conditions unsafe for SCUBA diving on 3 occasions and this increased the number of days between successive removal of sediments to $4 \mathrm{~d}$ (twice) and $6 \mathrm{~d}$ (once).

Quantification of ecological responses to treatments. In August, 65 d after treatments were applied, all experimental plates were placed into sealed plastic bags and taken back to the laboratory for quantifica- tion of percentage cover of epibiota. In most cases, invertebrates were identified to species, while algae were identified as red algae, green algae, or brown turfing algae given that the identification of juvenile specimens to species level was difficult and was not required to provide an adequate test of the primary hypothesis. Survivorship of tubiculous polychaete worms among treatments was estimated by counting the number of tubes with worms present (alive) and with worms absent (dead). Tubes were opened on each plate until all individuals of a taxon were sampled or the number of individuals examined reached 50 .

Quantification of physical variables and potential artefacts. Relative differences in light intensity, sediment deposition and water flow were estimated for each level of light intensity. Additional roofs that lacked experimental plates below them were constructed ( $n=5$ per treatment) to obtain these estimates, because it could not be assumed that the techniques used to measure physical variables (i.e. light meters, sediment traps and plaster clods) would not interfere with the survival and development of epibiota on experimental plates. Light intensity was quantified with remote light meters $\left(\mathrm{HOBO}^{\circledR}\right.$ LI data loggers) positioned the same distance under the roofs as the experimental plates. Light intensity was simultaneously recorded among 3 treatments (full shade, procedural control, open plates) with 15 loggers (3 treatments $\times 5$ loggers) once per minute for $25 \mathrm{~h}$.

Although experimental manipulations of light have used roofs without altering rates of sediment accumulation (e.g. Glasby 1999a), clear perspex roofs can reduce rates of sediment accumulation and influence the subtidal algae (Airoldi \& Cinelli 1997). For this reason, a comparison of rates of sedimentation between open surfaces and those with black and clear roofs was intended to aid interpretation of any experimental effects. Rates of sedimentation among treatments were quantified on 4 occasions with sediment traps made of PVC cylinders $(170 \mathrm{~mm}$ high $\times 50 \mathrm{~mm}$ diameter: aspect ratio $>3$ as recommended by Håkanson et al. 1989). Sediment traps were positioned so that their openings were the same height from the sea floor as plate surfaces, as well as the same distance away from roofs as plate surfaces. Traps were collected within $12 \mathrm{~d}$ of deployment, sieved into a coarse fraction $(>250 \mu \mathrm{m})$ and a fine fraction $(<250 \mu \mathrm{m})$ before being oven dried to constant weight $\left(70^{\circ} \mathrm{C}\right.$ for $\left.48 \mathrm{~h}\right)$.

The presence of the shading structures also might alter water flow over plates. Plaster clods were used to test for relative differences in flow between roofed and unroofed treatments. Clods were dried at $70^{\circ} \mathrm{C}$ for $48 \mathrm{~h}$ and weighed prior to being attached to the wire mesh frame under black and clear roofs and in open areas. Clods were collected after $6 \mathrm{~d}$ and were dried to a con- 
stant weight at $70^{\circ} \mathrm{C}$ for $48 \mathrm{~h}$ before being re-weighed. The percentage dissolution of each clod was then determined.

Analytical and statistical procedures. Analyses proceeded in 3 steps. Step 1 tested the effectiveness of treatments and tested for artefacts associated with disturbance (multivariate effects of rotating plates on assemblage structure), experimental structures (univariate tests of flow and sedimentation among treatments) and whether experimental structures directly altered assemblages (multivariate test of differences between assemblages on open plates and plates under clear roofs). Step 2 tested for independent and interactive effects of light and sedimentation on epibiotic assemblages (multivariate tests). Step 3 tested for experimental effects on the percentage cover and survivorship of individual taxa (univariate tests).

Non-parametric multivariate analysis of variance (NPMANOVA, Anderson 2001) was done for all multivariate analyses of assemblage structure. Replicates were $4 \sqrt{ }$ transformed before dissimilarities among replicates were calculated with the Bray-Curtis measure. The factors of sedimentation and shade were treated as fixed and crossed (in both multivariate and univariate tests) and all permutations were done on the full model (Anderson 2001). Univariate analyses were done using 2-way ANOVAs following Underwood (1997). Significance was judged at $\alpha=0.05$ unless Cochran's $C$-test detected heterogeneous variances, in which case significance was judged at a more conservative probability of 0.01 . Student-Newman-Keuls (SNK) tests located differences among treatments following univariate analyses.

\section{RESULTS}

\section{Assemblages associated with up- and down-facing surfaces}

Prior to rotation (i.e. after $100 \mathrm{~d}$ of submergence), the only taxa with extensive coverage on up-facing surfaces were red algae (Laurencia spp.: $14.8 \% \pm 10.9 \mathrm{SE}$ ) and green algae (Cladophorales and Ulvales: $6.5 \% \pm$ $0.8 \mathrm{SE})$. Brown algae were rare $(0.5 \% \pm 0.2 \mathrm{SE})$, no invertebrate taxa were recorded, and bare space/sediment was extensive $(79 \% \pm 1.7 \mathrm{SE})$. Assemblages on down-facing surfaces were dominated by serpulid (Galeolaria hystrix: 59.6\% $\pm 2.3 \mathrm{SE}$ and Pomatoceros taeniatus: $1.9 \% \pm 0.3 \mathrm{SE}$ ) and spirorbid polychaetes $(4.0 \% \pm 0.4 \mathrm{SE})$, as well as small $(<2 \mathrm{~cm}$ long) oysters (Ostreidae: $14.8 \% \pm 1.4 \mathrm{SE}$ ). No algae were recorded and bare space was present $(15.7 \% \pm 1.8 \mathrm{SE})$. The greater covers of algae on the up-facing and invertebrates on the down-facing surfaces were consistent with initial conditions required to test the hypothesis.

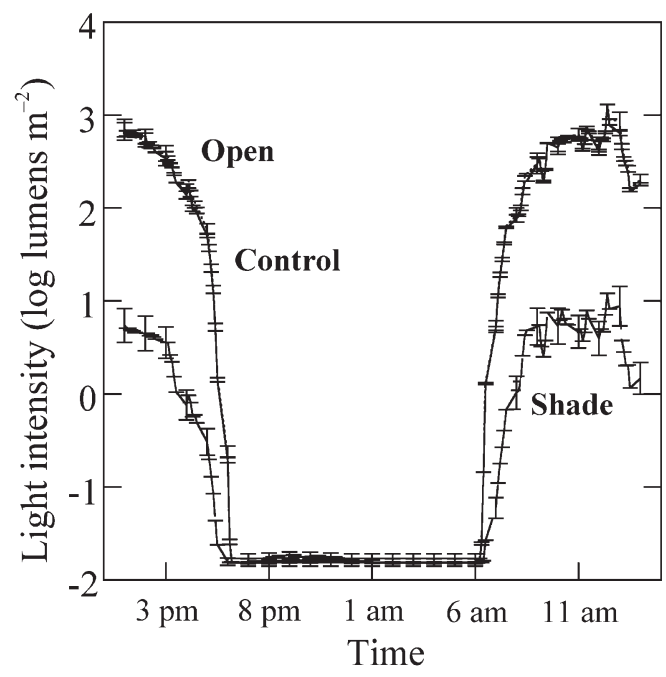

Fig. 1. Light intensity (log lumens $\mathrm{m}^{-2} \pm \mathrm{SE}$ ) among open, procedural control (clear roofs), and shaded treatments (black roofs). Open and procedural controls overlap completely; SE bars plotted every hour

\section{Effectiveness of treatments and tests of artefacts}

Light intensity under black roofs was considerably less than over open plates and under clear roofs during daylight (Fig. 1). These differences were detected for an $8 \mathrm{~h}$ period of daylight in which readings were averaged within each treatment (ANOVA: $F_{2,12}=117.32$, $\mathrm{p}<0.001$; SNK tests: open $=$ procedural control $>$ shade). Rates of sedimentation did not differ among the 3 treatments (Fig. 2) and ANOVA on the period most likely to reveal differences (14 to 26 July, sampling period 3) failed to detect an effect of roofs (ANOVA: $F_{2,12}=0.61, \mathrm{p}>0.50$ ). The uncharacteristically large amounts of sediment observed over the 3rd

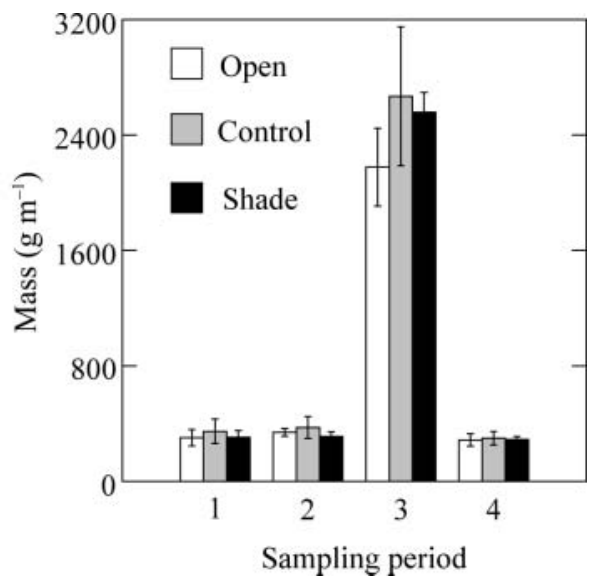

Fig. 2. Sedimentation $\left(\mathrm{g} \mathrm{m}^{-2} \pm \mathrm{SE}\right)$ in open, procedural control, and shaded treatments. Sampling periods: (1) 26 June to 1 July, (2) 1 to 11 July, (3) 14 to 26 July, and (4) 3 to 11 August 
Table 1. NP-MANOVA testing the effects of light (reduced light vs natural) and sediment (reduced vs natural) on the maintenance of epibiotic assemblages. ${ }^{*} \mathrm{p}<0.05,{ }^{* * *} \mathrm{p}<0.001$

\begin{tabular}{|lrrrc|}
\hline Source & df & MS & $F$ & $\mathrm{p}$ \\
\hline Light & 1 & 1371.81 & 11.49 & ${ }^{* * *}$ \\
Sediment & 1 & 174.29 & 1.46 & 0.24 \\
Light $\times$ Sediment & 1 & 399.52 & 3.35 & ${ }^{*}$ \\
Residual & 16 & 119.42 & & \\
Total & 19 & & & \\
\hline
\end{tabular}

sampling period were associated with a storm. Dissolution of plaster (and hence water flow) did not differ between roofed and open treatments (ANOVA: $F_{2,12}=$ $2.28, \mathrm{p}>0.10)$.

No effect of disturbance associated with rotation on assemblage structure was detected. Two-way NPMANOVA failed to detect differences between rotated and untouched plates (main term for disturbance: $F_{1,16}$ $=-0.47, p>0.75$ ) or its interaction with orientation (disturbance $\times$ orientation: $\left.F_{1,16}=-0.76, p>0.54\right)$. A test of potential artefacts associated with the roof structures was achieved by comparing the composition and percentage cover of epibiotic assemblages between open plates and plates under clear roofs. Importantly, this comparison failed to detect differences for either level of sedimentation (NP-MANOVA: $F_{1,16}=0.95, p>0.25$ ) or the interaction between presence and absence of roofs and each level of sedimentation (NP-MANOVA: $\left.F_{1,16}=0.034, \mathrm{p}>0.25\right)$, meaning that direct comparisons among natural light (open) and shaded treatments could be logically interpreted.

\section{Effects of light and sedimentation on maintenance of epibiotic assemblages}

NP-MANOVA detected an interaction between light and sediment (Table 1) with a posteriori comparisons revealing that the effects of sedimentation occurred only under conditions of low light intensity. Removal of sediments had no effect on epibiota under natural light intensity (reduced $=$ natural $;$ p > 0.05), but significantly impacted shaded epibiota (reduced $=$ natural: $\mathrm{p}<0.05$ ). Furthermore, assemblages under shade differed from those in natural light within each treatment of reduced and natural sedimentation (shade $\neq$ natural: $\mathrm{p}<0.05$ ).

Comparison of Bray-Curtis distances from all replicates indicated that while sedimentation had strong effects on assemblage structure, shade primarily maintained assemblages of epibiota (Fig. 3, Table 2; c.f. 'Down' with other treatments in that row). As expected, the largest difference was between up- and down-facing surfaces of untouched plates (cf. 'Up' vs

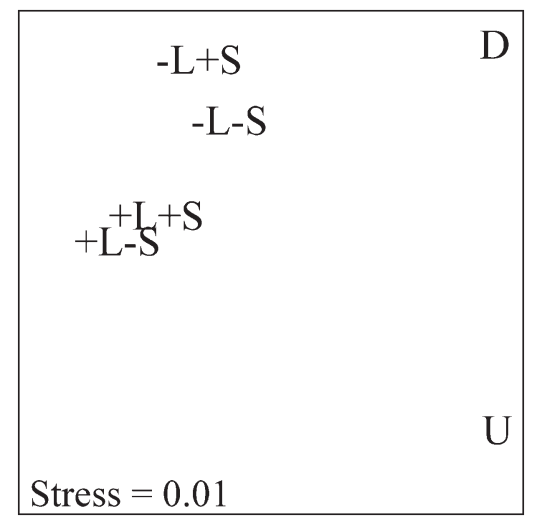

Fig. 3. nMDS plot of structure of assemblages of epibiota on panels that were (D) down-facing, (U) up-facing compared to up-facing panels subjected to paired combinations of $(+\mathrm{L})$ natural light, (-L) shade, (+S) natural sedimentation and $(-\mathrm{S})$ reduced sedimentation. Replicate panels have been averaged within each treatment

'Down'). The assemblages that developed to become most similar to untouched up-facing surface assemblages were those under natural regimes of light and sedimentation (cf. ' $U p^{\prime}$ ' with other treatments in that row). The remaining pairwise comparisons confirm the observation that differences in assemblage structure were greatest between unshaded and shaded treatments than between reduced and natural rates of sedimentation (cf. \pm shade and \pm sediment combinations).

\section{Effects on abundance and survivorship of individual taxa}

Apart from spirorbid polychaetes, all taxa on plates prior to rotation were still recorded $65 \mathrm{~d}$ after transplantation and are analysed here. These analyses also include new colonisers: soft-tube building polychaetes (Sabellastarte spp., Sabellidae), red algae (Laurencia spp.), green algae (Cladophorales and Ulvales) as well

Table 2. Bray-Curtis measures of dissimilarity of assemblage structure among treatments (the smaller the value the more similar the assemblage). 'Down' and 'Up'-facing surfaces of untouched plates compared with translocated panels among treatments of shade $(-\mathrm{L})$, no shade $(+\mathrm{L})$, natural sedimentation $(+\mathrm{S})$ and reduced sedimentation $(-\mathrm{S})$

\begin{tabular}{|lccccc|}
\hline Treatment & $-\mathrm{L}-\mathrm{S}$ & $-\mathrm{L}+\mathrm{S}$ & $+\mathrm{L}-\mathrm{S}$ & $+\mathrm{L}+\mathrm{S}$ & $\mathrm{Up}$ \\
\hline Down & 28.31 & 23.48 & 31.44 & 30.08 & 97.42 \\
Up & 71.16 & 76.24 & 59.25 & 54.76 & \\
$+\mathrm{L}+\mathrm{S}$ & 24.12 & 24.03 & 14.19 & & \\
$+\mathrm{L}-\mathrm{S}$ & 19.02 & 21.16 & & & \\
$-\mathrm{L}+\mathrm{S}$ & 18.57 & & & & \\
\hline
\end{tabular}


as a species of Feldmannia (Phaeophyta) that formed densely packed turfs.

No effect of treatment was detected on the percentage cover of the hard-shelled invertebrates: Galeolaria hystrix, Pomatoceros taeniatus, and oysters (Fig. $4 \mathrm{a}-\mathrm{c}$, Table 3). However, significant main effects of light and sediment were found for the percentage cover of Sabellastarte spp. (Fig. 4d, Table 3). These taxa covered a greater proportion of shaded plates independent of sediment accumulation (SNK tests: Shade $>$ Open $=$ Control) and plates exposed to natural rates of sedimentation (SNK tests: natural > reduced sedimentation).

Percentage cover of algae was least under shaded conditions regardless of the rate of sedimentation (Fig. 4e; Table 3, SNK tests). However, percentage cover was greatest on plates from which sediment was removed, independent of shade. Individual groups of algae (reds: $2.3 \% \pm 1.0 \mathrm{SE}$; greens: $3.5 \% \pm 1.8 \mathrm{SE}$; Feldmannia turfs $3.8 \% \pm 1.1 \mathrm{SE}$ ) were not analysed separately, because their numerical abundance was insufficient for interpretable univariate analysis. Despite this, comparisons of percentage cover for each of these taxa revealed that rank-abundance was consistently greater in treatments with lower sedimentation and natural light intensity. When low vs high rates of sedi- mentation are compared for each taxon and treatment of light ( 3 taxa $\times 3$ light), 8 of 9 pairwise comparisons supporting the negative effects of sedimentation are unlikely by chance alone (binomial [sign] test for paired data, $p<0.05$; Underwood 1997). Similarly, when low (shade) vs natural light intensity (open) are compared for each taxon and treatment of sedimentation ( 3 taxa $\times 2$ sediment), 6 of 6 comparisons supporting the negative effects of shade are unlikely by chance alone (binomial test, $\mathrm{p}<0.05$ ).

The survivorship of the tube building polychaetes appeared to be related to their form of growth. Survivorship of the prostrate (horizontal) growth forms of polychaetes, Galeolaria hystrix and Pomatoceros taeniatus, was significantly reduced under natural rates of sedimentation regardless of light intensity (Fig. 5, Table 4). The survivorship of the erect (vertical) growing Sabellastarte spp., however, was not significantly affected by either light or sediment (Fig. 5, Table 4).

\section{DISCUSSION}

Experimental tests of the effects of sedimentation and light on whole assemblages of epibiota (algae and (a) Galeolaria hystrix

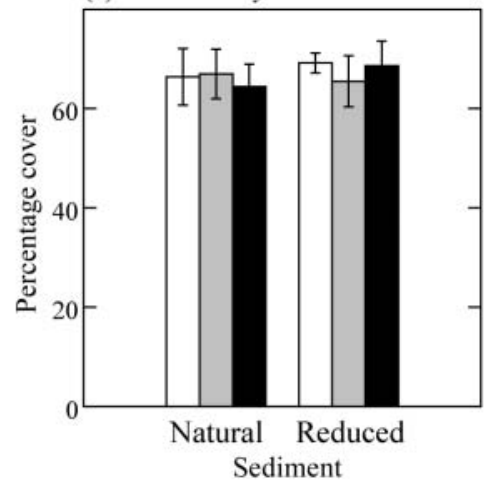

(d) Sabellastarte sp.

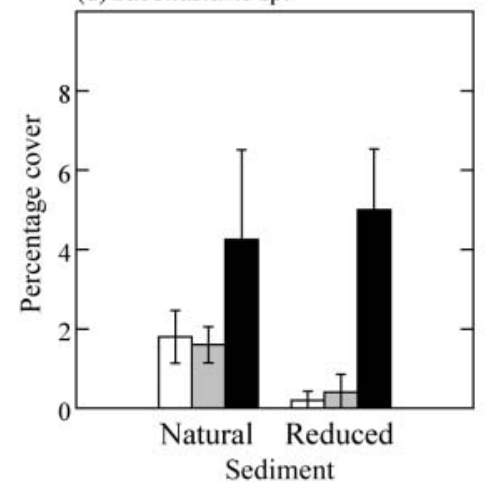

(b) Pomatoceros taeniatus

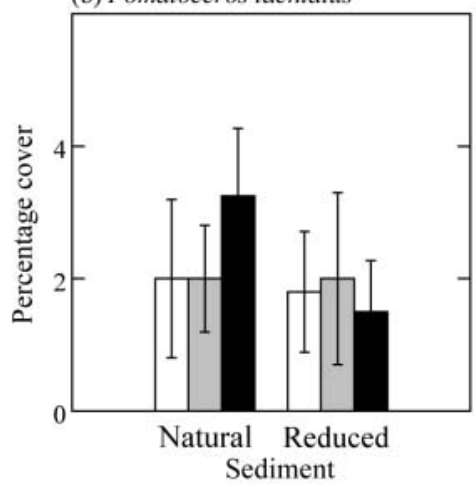

(e) Total algae

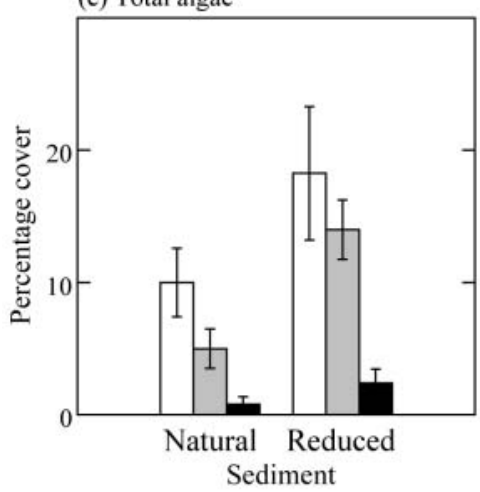

(c) Oyster

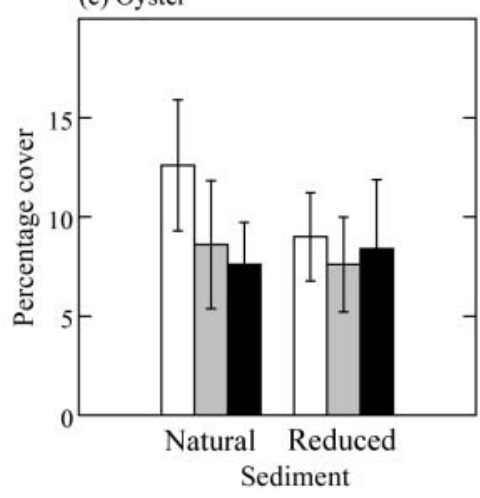

Fig. 4. Percentage cover $( \pm \mathrm{SE})$ of taxa on panels subjected to natural and reduced rates of sedimentation within treatments of natural light (open, control) and reduced light (shade) 
Table 3. Analysis of variance testing for differences in percentage cover of individual taxa among manipulations of sediment and light. Data were arcsine (square-root) transformed. Cochran's $C$-test $\mathrm{p}>0.05$ for all taxa. Sediment and light were treated as fixed and orthogonal. ${ }^{*} p<0.05,{ }^{* * *} p<0.001$

\begin{tabular}{|c|c|c|c|c|}
\hline $\begin{array}{l}\text { Taxa } \\
\quad \text { Source }\end{array}$ & df & MS & $F$ & $\mathrm{p}$ \\
\hline \multicolumn{5}{|l|}{ Galeolaria hystrix } \\
\hline Sediment & 1 & 9.52 & 0.29 & 0.59 \\
\hline Light & 2 & 7.40 & 0.23 & 0.80 \\
\hline Sediment $\times$ Light & 2 & 7.55 & 0.23 & 0.80 \\
\hline Residual & 24 & 32.61 & & \\
\hline \multicolumn{5}{|l|}{ Pomatoceros taeniatus } \\
\hline Sediment & 1 & 18.35 & 0.63 & 0.44 \\
\hline Light & 2 & 37.55 & 1.29 & 0.29 \\
\hline Sediment $\times$ Light & 2 & 7.55 & 0.26 & 0.77 \\
\hline Residual & 24 & 29.09 & & \\
\hline \multicolumn{5}{|l|}{ Ostreidae } \\
\hline Sediment & 1 & 18.78 & 0.54 & 0.47 \\
\hline Light & 2 & 23.33 & 0.67 & 0.52 \\
\hline Sediment $\times$ Light & 2 & 4.18 & 0.12 & 0.89 \\
\hline Residual & 24 & 34.87 & & \\
\hline \multicolumn{5}{|l|}{ Sabellastarte spp. } \\
\hline Sediment & 1 & 112.78 & 4.80 & ${ }^{*}$ \\
\hline Light & 2 & 249.86 & 10.63 & ${ }^{* * *}$ \\
\hline Sediment $\times$ Light & 2 & 20.42 & 0.87 & 0.43 \\
\hline Residual & 24 & 23.51 & & \\
\hline \multicolumn{5}{|l|}{ Algae } \\
\hline Sediment & 1 & 512.78 & 19.47 & $* * *$ \\
\hline Light & 2 & 595.56 & 22.62 & $* * *$ \\
\hline Sediment $\times$ Light & 2 & 54.80 & 2.08 & 0.15 \\
\hline Residual & 24 & 26.33 & & \\
\hline
\end{tabular}

invertebrates) are rare and have focused on one or the other of these factors in isolation. Our results demonstrate that epibiotic assemblages are affected by the combination of these factors. In nature, increased sedimentation is likely to reduce light intensity through increased turbidity (Ruffin 1998) and our experiment demonstrates that sedimentation had negligible effects under natural light, but caused changes to the structure of whole assemblages under shaded conditions.
Table 4. ANOVA testing differences in percentage survivorship of tubiculous polychaetes among treatments of sedimentation and light. Data were arcsine (square-root) transformed ${ }^{* * *} \mathrm{p}<0.001$

\begin{tabular}{|c|c|c|c|c|}
\hline $\begin{array}{l}\text { Taxa } \\
\quad \text { Source }\end{array}$ & df & MS & $F$ & $\mathrm{p}$ \\
\hline \multicolumn{5}{|l|}{ Galeolaria hystrix } \\
\hline Sediment & 1 & 4368.09 & 173.62 & $* * *$ \\
\hline Light & 2 & 38.51 & 1.53 & 0.24 \\
\hline Sediment $\times$ Light & 2 & 35.76 & 1.42 & 0.26 \\
\hline Residual & 24 & 25.16 & & \\
\hline \multicolumn{5}{|l|}{ Pomatoceros taeniatus } \\
\hline Sediment & 1 & 9663.79 & 36.56 & *** \\
\hline Light & 2 & 399.21 & 1.51 & 0.24 \\
\hline Sediment $\times$ Light & 2 & 191.26 & 0.72 & 0.50 \\
\hline Residual & 24 & 264.36 & & \\
\hline \multicolumn{5}{|l|}{ Sabellastarte spp. } \\
\hline Sediment & 1 & 287.28 & 3.02 & 0.09 \\
\hline Light & 2 & 167.40 & 1.76 & 0.19 \\
\hline Sediment $\times$ Light & 2 & 167.40 & 1.76 & 0.19 \\
\hline Residual & 24 & 94.97 & & \\
\hline
\end{tabular}

This interactive effect was less apparent within individual groups of taxa.

The greater abundance of subtidal algae on up-facing surfaces appears to be primarily dependent on light intensity, as expected from taxa with photosynthetic obligations, but this experiment provides direct evidence that sedimentation may be more important than previous single-factor tests suggest. This is because enhanced sedimentation and reduced light intensity tend to be correlated in nature, and our experiment demonstrates that this combination has a greater negative effect than either factor in isolation.

The observation that sessile invertebrates dominate shaded surfaces (James \& Underwood 1994, Baynes 1999, Glasby 1999b) is often explained by long-standing laboratory observations of larval behaviour; that is, many species become photonegative as they end their pelagic larval phase (Thorson 1964, Dirnberger 1993).
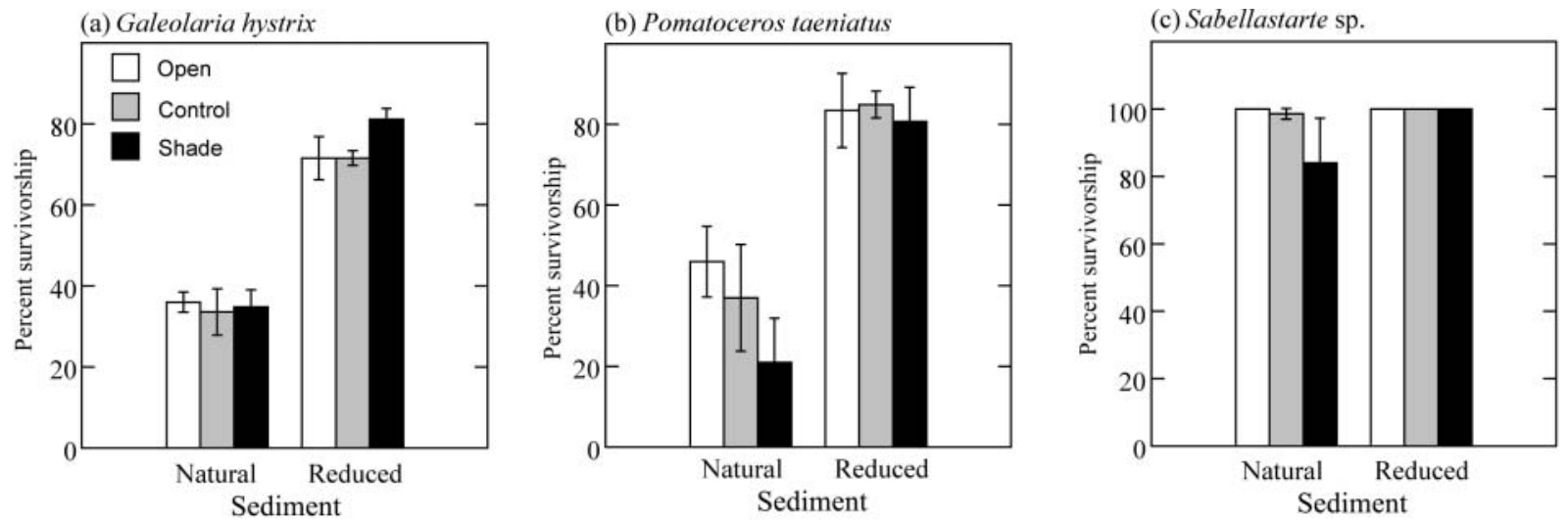

Fig. 5. Percent survivorship $( \pm \mathrm{SE})$ of tubiculous polychaetes on panels subjected to natural and reduced rates of sedimentation among treatments in natural light (open, control) and reduced light (shade) 
Indeed, field experiments show that it is only in the presence of shade that the recruitment of invertebrates responds to surface orientation; e.g. up- and downfacing surfaces (Saunders \& Connell 2001). Although this importance of shade has become a widely accepted paradigm, few have suggested that these positive effects of shade may also correlate with the positive effects of lower sediment accumulation (but see Maldonado \& Young 1996).

Although the direct effects of sedimentation on the structure of epibiotic assemblages have rarely been tested, there is evidence that the physiology of some invertebrates is negatively affected by increased sedimentation (Gerodette \& Flechsig 1979, Young \& Chia 1984) and the structure of epibiotic assemblages varies along gradients of sedimentation (Daly \& Mathieson 1977, Salinas \& Urdangarin 1994, Carballo et al. 1996, Naranjo et al. 1996, Roberts et al. 1998). Our work provides some of the first direct experimental evidence of the effects of sedimentation on the survivorship of invertebrates. The results suggest that invertebrates can be negatively affected by sediment and hence survive better and develop more abundantly on surfaces that have low rates of sedimentation. Because such surfaces are often also shaded (i.e. vertical and downfacing surfaces), the current results demonstrate that shade and sedimentation can combine to cause greater abundances and diversities of subtidal invertebrates on surfaces of such orientations (e.g. rock walls, overhangs, undersides of boulders, and caves).

Our experiments also suggest that sedimentation and shade combine to have different effects on taxa which relate to their morphology (erect vs prostrate growth forms) and physiology (photosynthetic plants vs photonegative larvae). The ability of 3 related species of marine invertebrates (tubiculous polychaetes) to withstand sedimentation was related to whether they grew erect and above accumulated sediments (unaffected by sedimentation) or prostrate to the substratum and smothered by sediments (negatively affected by sedimentation). Consequently, survivorship in prostrate forms was much greater under conditions of low than high sediment accumulation, but had no effect on erect forms. These differences in survivorship did not translate into greater abundances among treatments of lower sedimentation, possibly because estimates of percentage cover did not distinguish between live and dead individuals.

Our results warn that while light intensity may be a good predictor of abundances of sessile invertebrates between surface orientations, it may not always be the primary cause of these patterns. If sediment accumulation is detrimental to survival, cues that enable larvae to settle to shaded surfaces may allow older life stages to avoid the negative effects of sedimentation. So, if shade primarily affects the locality of settlement (where the animal is destined to live the rest of its life) and sediments affect its capacity to survive and recruit into the adult population, it is reasonable to view the recruitment of these taxa in 2 phases. The recruitment of the tubiculous polychaetes G. hystrix and P. taeniatus appears to be mediated by the physical factor of light initially and then sedimentation later. Shade facilitates early recruitment, but the physical disturbance of sedimentation reduces survival and their recruitment to adult populations on surfaces that accumulate sediment. Hence, shade (facilitator of settlement) and sediment (disturbance) combine in different ways to shape the abundances of invertebrates and the role of these combinations will be dependent on surface orientation.

In conclusion, although sedimentation appeared to play a smaller role than shade in maintaining habitat heterogeneity, these results reinforce emerging evidence that increased sediment loads have negative effects on both algae and invertebrates. Importantly, any negative effect of sedimentation was negligible under conditions of natural light intensity, but was detected when light intensity was reduced. This result warns that attempts to identify the effects of sedimentation in isolation from light intensity, which are not independent in nature (because of turbidity), may not reveal the true effects of sedimentation on assemblages of invertebrates. Although the generality of these results are not yet known with our results derived from a single location and season (winter) using settlement plates, similar experimental results occur in the colonisation of new space (summer) and maintenance of existing assemblages $(11 \mathrm{mo})$ on natural rocky reef some hundreds of kilometres away (Connell unpubl.).

The heterogeneity of algal and invertebrate dominated assemblages was primarily maintained by light intensity which increased coverage of algae on upfacing surfaces (natural light) and invertebrates on down-facing surfaces (reduced light). A predictive understanding of the structure within invertebrate dominated assemblages may require knowledge of how differences in morphology of taxa respond to physical processes of facilitation and disturbance. Facilitation (e.g. light intensity) and disturbance (e.g. sedimentation) are unlikely to operate independently of each other and although physical processes are seldom tested in combination by ecologists, we can benefit from tests of hypotheses that explain their interactions. Most experimental work on physical facilitation and disturbance concerns the dynamics of space release and occupancy, yet there is little understanding of how these processes maintain assemblages without the creation or provision of new space. In 
many habitats, it is likely that the creation of space is only one of a number of natural disturbances that maintain habitat heterogeneity. Testing of hypotheses on the effects of physical processes on existing assemblages would lead to a better understanding of the processes that maintain the heterogeneity of epibiotic assemblages.

Acknowledgements. This project could not have been achieved without the assistance of L. Ashwin, M. Eliades, T. Elsdon, G. Irving, B. Irving and S. Sparkes. We thank T. Glasby and 3 anonymous reviewers for critical comments that improved the manuscript. This research was supported by an AR Riddle scholarship to A.D.I. and an Australian Research Council Grant to S.D.C.

\section{LITERATURE CITED}

Airoldi L, Cinelli F (1997) Effects of sedimentation on subtidal macroalgal assemblages: an experimental study from a Mediterranean rocky shore. J Exp Mar Biol Ecol 215: 269-288

Airoldi L, Virgilio M (1998) Responses of turf-forming algae to spatial variations in the deposition of sediments. Mar Ecol Prog Ser 165:271-282

Anderson MJ (2001) A new method for non-parametric multivariate analysis of variance in ecology. Aust Ecol 26:32-46

Baynes TW (1999) Factors structuring a subtidal encrusting community in the southern Gulf of California. Bull Mar Sci 64:419-450

Beardall J, Beer S, Raven JA (1998) Biodiversity of marine plants in an era of climate change: some predictions based on physiological performance. Bot Mar 41:113-123

Carballo JL, Naranjo SA, Garcia-Gomez JC (1996) The use of sponges as stress indicators in marine ecosystems at Algeciras Bay (southern Iberian Peninsula). Mar Ecol Prog Ser 135:109-122

Daly MA, Mathieson AC (1977) The effects of sand movement on intertidal seaweeds and selected invertebrates at Bound Rock, New Hampshire, USA. Mar Biol 43:45-55

Dirnberger JM (1993) Dispersal of larvae with a short planktonic phase in the polychaete Spirorbis spirillum (Linnaeus). Bull Mar Sci 52:898-910

Franklin LA, Forster RM (1997) The changing irradiance environment: consequences for marine macrophyte physiology, productivity and ecology. Eur J Phycol 32:207-232

Gerodette T, Flechsig AO (1979) Sediment-induced reduction in the pumping rate of the tropical sponge Verongia lacunosa. Mar Biol 55:103-110

Glasby TM (1999a) Interactive effects of shading and proximity to the seafloor on the development of subtidal epibiotic assemblages. Mar Ecol Prog Ser 190:113-124

Glasby TM (1999b) Effects of shading on subtidal epibiotic assemblages. J Exp Mar Biol Ecol 234:275-290

Glasby TM, Connell SD (2001) Orientation and position of substratum have large effects on epibiotic assemblages. Mar Ecol Prog Ser 214:127-135

Håkanson L, Floderus S, Wallin M (1989) Sediment trap assemblages - a methodological description. Hydrobiologia 176/177:481-490

Irving AD, Connell SD (2002) Interactive effects of sedimentation and microtopography on the abundance of subtidal turf-forming algae. Phycologia 41:517-522

Editorial responsibility: Tony Underwood (Contributing Editor), Sydney, Australia
James PL, Larkum AWD (1996) Photosynthetic inorganic carbon acquisition of Posidonia australis. Aquat Bot 55: 149-157

James RJ, Underwood AJ (1994) Influence of colour of substratum on recruitment of spirorbid tubeworms to different types of intertidal boulders. J Exp Mar Biol Ecol 181: 105-115

Jokiel PL (1980) Solar ultraviolet radiation and coral reef epifauna. Science 207:1069-1071

Kendrick GA (1991) Recruitment of coralline crusts and filamentous turf algae in the Galapagos Archipelago: effect of sediment scour, erosion and accretion. J Exp Mar Biol Ecol 147:47-63

Kennelly SJ (1989) Effects of kelp canopies on understorey species due to shade and scour. J Exp Mar Biol Ecol 168: $35-58$

Maldonado M, Young CM (1996) Effects of physical factors on larval behaviour, settlement and recruitment of 4 tropical demosponges. Mar Ecol Prog Ser 138:169-180

Naranjo SA, Carballo JL, Garcia-Gomez JC (1996) Effects of environmental stress on ascidian populations in Algeciras Bay (southern Spain). Possible marine bioindicators? Mar Ecol Prog Ser 144:45-71

Osman RW (1977) The establishment and development of a marine epifaunal community. Ecol Monogr 47:37-63

Raven JA (1991) Responses of aquatic photosynthetic organisms to increased solar UVB. J Photochem Photobiol B: Biol 9:239-244

Reed DC, Foster MS (1984) The effects of canopy shading on algal recruitment and growth in a giant kelp forest. Ecology 65:937-948

Roberts DE, Smith A, Ajani P, Davis AR (1998) Rapid changes in encrusting marine assemblages exposed to anthropogenic point-source pollution: a 'Beyond BACI' approach. Mar Ecol Prog Ser 163:213-224

Ruffin KK (1998) The persistence of anthropogenic turbidity plumes in a shallow water estuary. Estuar Coast Shelf Sci 47:579-592

Salinas JIS, Urdangarin II (1994) Response of sublittoral hard substrate invertebrates to estuarine sedimentation in the outer harbour of Bilbao (N. Spain). PSZN I: Mar Ecol 65: 937-948

Saunders RJ, Connell SD (2001) Interactive effects of shade and surface orientation on the recruitment of spirorbid polychaetes. Aust Ecol 26:109-115

Thorson G (1964) Light as an ecological factor in the dispersal and settlement of larvae of marine bottom invertebrates. Ophelia 1:167-208

Todd CD, Turner SJ (1986) Ecology of intertidal and sublittoral cryptic epifaunal assemblages. I Experimental rationale and the analysis of larval settlement. J Exp Mar Biol Ecol 99:199-231

Umar MJ, McCook LJ, Price IR (1998) Effects of sediment deposition on the seaweed Sargassum on a fringing coral reef. Coral Reefs 17:169-177

Underwood AJ (1997) Experiments in ecology. Their logical design and interpretation using analysis of variance. Cambridge University Press, Cambridge

Withers RG, Thorp CH (1977) Studies on the shallow, sublittoral epibenthos of Langstone Harbour, Hampshire, using settlement plates. In: Keegan BF, Ceidigh PO, Boaden PJS (eds) Biology of benthic organisms. Pergamon Press, London, p 595-604

Young CM, Chia FS (1984) Microhabitat-associated variability in survival and growth of subtidal solitary ascidians during the first $21 \mathrm{~d}$ after settlement. Mar Biol 81:61-68 